\title{
Digital Design in Artistic Education: An Overview of Research in the University Setting
}

\author{
Mariana-Daniela González-Zamar ${ }^{1, *(D)}$ and Emilio Abad-Segura $2, *$ (D) \\ 1 Department of Education, University of Almeria, 04120 Almeria, Spain \\ 2 Department of Economics and Business, University of Almeria, 04120 Almeria, Spain \\ * Correspondence: mgz857@ual.es (M.-D.G.-Z.); eas297@ual.es (E.A.-S.)
}

Citation: González-Zamar, M.-D.; Abad-Segura, E. Digital Design in Artistic Education: An Overview of Research in the University Setting. Educ. Sci. 2021, 11, 144. https:// doi.org/10.3390/educsci11040144

Academic Editor: James Albright

Received: 18 February 2021

Accepted: 18 March 2021

Published: 24 March 2021

Publisher's Note: MDPI stays neutral with regard to jurisdictional claims in published maps and institutional affiliations.

Copyright: (c) 2021 by the authors. Licensee MDPI, Basel, Switzerland. This article is an open access article distributed under the terms and conditions of the Creative Commons Attribution (CC BY) license (https:// creativecommons.org/licenses/by/ $4.0 /)$.

\begin{abstract}
Digital design processes in artistic education promote the development of autonomy and self-critical capacities among students. Digital technology has transformed university education and the development of transversal skills. The objective of this study is to analyze research on digital design in art education in the context of higher education during the period 2000-2020. Bibliometric techniques were applied to 1027 articles selected from the Scopus database. The findings yielded data on the scientific productivity of journals, authors, research institutions and countries/territories that promote this topic. The data show an exponential trend, with more insistence in the last three years. Six current schools of knowledge related to art, level, formation, faculty, perception and relationship were detected. This research establishes the link between education, art and technology in the university context, and it is a tool for decision making by promoters of this field of research.
\end{abstract}

Keywords: artistic education; digital art; design; creativity; technology; research

\section{Introduction}

At a global level, there have been economic, social and technological transformations that have led to a change in the role of higher education institutions (HEIs) in today's society [1]. Likewise, universities must foster an integrated continuity between the present and the future, and between theory and practice, to prepare students so that what they learn today can be applied in their future work experience.

In other words, these changes are related to empowering students through a holistic educational approach, allowing them to improve their skills and abilities. In this perspective, competency assessment, introduced in 2010 with the Bologna Plan and the European Higher Education Area (EHEA), seeks among its objectives to bring education closer to work practice and prepare the student for new work challenges [2,3]. One of the key skills to face these challenges and progress in the present complex context is digital design in artistic education. The promotion of creativity and artistic teachings, even at university, enables young people to develop creative and divergent thinking. It has been pushed to respond to the issues posed by the different social sectors to prepare young professionals for today's changing world [4].

In the context of digital design in artistic education, the artistic skills acquired act as a competitive advantage over other students who have not developed them during their academic process. Hence, art education focuses on digital aspects in order to prepare university students to face the uncertain future, nurturing creativity, creative thinking and imagination when solving problems [5]. The emergence of information and communication technologies (ICT) led to the advancement of new methodological models through a digital ecosystem, which represents great interest due to its enormous educational and creative potential [6].

In the literature reviewed, various concepts on art, artistic, creativity, design process and digital technology applied to higher education (HE) were found. It is important to understand the teaching of artistic education as a general field of education. Different 
academic currents have defended the incorporation of the arts into education, pointing out that they should be part of the curriculum, promoting the development of creativity, individual expression and the recognition of the various forms of expression.

Numerous studies question the causes of low development and dedication to creative thinking during high school and HE $[7,8]$. The panorama would be very different if HEIs, as institutions committed to a holistic training of the individual, used creativity and the arts as an instrument to favorably manage creative thinking as a cross-cutting theme along the academic path of the individual.

The digital presence encourages HEIs to adapt to new business models, such as innovation in personnel structures. In this sense, digital transformation makes it possible, through big data and the Internet of Things (IoT), for students to personalize their training, incorporating e-learning and b-learning as learning alternatives, proposing a socializing dimension technology $[9,10]$. HE faces the challenge of adapting and responding to the changes that digitization has introduced.

Likewise, the schools of knowledge refer to those lines of research that have an approach that encompasses knowledge, concerns, practices and perspectives of analysis of a particular subject of study, evidencing the future development of research in that line [11,12].

The purpose of the study was to detail how digital design have evolved to promote artistic education in the HE context. The literature reviewed made it possible to pose the following research questions about digital design in artistic education:

- How has scientific production evolved in the period analyzed? Possible causes that generated this evolution.

- What are the collaborative relationships between journals, authors, and countries/territories?

- What are the schools of knowledge developed in this period?

The aim was to analyze research during the period 2000-2020 on digital design in artistic education in the context of HE. To obtain answers to these questions, a sample of 1027 articles selected from the Scopus database was analyzed. The main contribution of this study was to determine the scientific literature and the cooperation networks between promoters of the theme of digital design in artistic education in HE. Furthermore, the main lines of research developed to date were identified.

Statistical techniques were used to achieve this objective. Bibliometric indicators allow knowing the evolution of publications in this field, in addition to understanding research trends. Among the research lines that are being carried out, these refer to the development of creativity through artistic design processes using ICT, which provide the student with new ways of approaching knowledge, or the study of proposals for digital designs which are more creative, efficient, and sustainable.

This study is structured as follows. Section 2 reveals the importance of the research topic, conducting a review of its basic concepts. Section 3 explains the methodology applied to the sample of selected articles. Section 4 shows and discusses the results in context. Finally, Section 5 includes the conclusions.

\section{Background and Theoretical Framework}

The reviewed literature provided definitions of variables about digital design in artistic education. In this section, the main terms used in this research are included, to avoid confusion regarding their interpretations.

The presence of art is as old as that of human beings, that is, its beginning coincides with the origin of humanity. Human beings are artists by nature, which is why, since the beginning of humanity, art has been a key element in our development and evolution, serving as a source, medium and form of expression [13]. Art is part of the tangible and intangible culture of a people, it represents a community, and its social role serves as an instrument for those who belong to it. In this sense, we focus on the usefulness of artistic expression that, combined with new technologies, functions as a tool to facilitate the development of creative and socio-educational skills in the individual $[14,15]$. 
It is relevant to remember that the term art, from the Latin artis, encompasses all creations made by humans to express a sensitive vision about the world, be it real or imaginary, using plastic and visual resources. This is where its usefulness resides and one of its ultimate purposes as an interaction tool is also manifested, allowing people to activate their senses, making known the perceptions that the environment generates in them and being able to express them together with their feelings, sensitizing the mind and the body with the world $[16,17]$.

Firstly, artistic education is defined as the connection in artistic and creative activities, such as painting, dance, theater, music or sculpture. Artistic education seeks to develop artistic thinking to express ideas and emotions and interpret the different codes of art $[5,18]$. It allows the development of capacities, attitudes, habits and actions, enhances abilities and skills and is also a means of interaction, communication and expression of feelings, emotions and attitudes, which allows the integral formation of the child, the young person and the adult $[3,15,19]$.

Another concept that intervenes in this study is digital art, which is a creative discipline of the plastic arts, a new trend that emerged around the application of vector and rewarding programs, including works that use essential digital elements in the production or exhibition process, shown on digital media. There are several kinds of digital art, among them photography and digital image, digital sculpture, interactivity, net art and finally generative art [20-22].

Digital art encompasses a series of creative disciplines in which digital technology is applied in the production process or in their exhibition. It integrates computer and digital technology, and there is a temptation to distinguish traditional art from digital, pointing out what is technological and what is not $[21,23]$. The technology basically consists in an instrument or procedure that enables creation, and in that sense, there is no difference between a brush and a graphic palette, but it is common to find classifications of digital art based on the medium used.

Design is defined as the prior process of mental configuration, that is, the prefiguration or search for a solution in any field. It is commonly applied in the context of art, engineering, architecture, communication and other disciplines that require creativity. The design involves various dimensions that go beyond appearance, shape and color, also encompassing the function of an object and its interaction with the user $[3,24]$. The design processes are the phases that the designer goes through. During the design process, the functionality, operability, efficiency and useful life of the design object must also be considered. Hence, from the moment an idea is conceived until it is concretized, every design object goes through a creative process that includes stages such as the idea, research, planning, prototype and its final construction $[25,26]$.

In recent decades, the arts were included in education for the first time, and this led to a debate around the need to incorporate them into other subject areas as well. The arts are a major part of the curriculum, since they develop creativity, self-expression and an appreciation for the expression of fellow students. Moreover, the art process promotes selfexpression, independence, flexible thinking, social interactions and the general well-being of the individual.

In the theory of multiple intelligences, it is argued that human beings possess various intellectual possibilities and that the development of these provide a basis for education in the arts [26-28]. Society is unaware of the impact of the arts on the development of children and young people, providing, among other benefits, the ability to observe the nuances of reality, expanding the way the world is perceived and often providing unobservable values, such as problem solving.

Numerous studies focused on the academic effects of arts-based learning have been shown to have a positive impact on character acuity, motivation, increased peer interactions and increased conflict resolution capacity, all of them required in a world in constant change. Throughout history, creativity has been described by artists, scientists and specialists from various areas and disciplines [29,30]. It is interesting to highlight those who consider 
the creative individual as a person capable of solving problems, developing products or defining new issues in each thematic field.

Other considerations focus on the fact that creativity is a human capacity that we all have, or it is a natural characteristic of the human mind linked potentially to all people. Imagination allows thinking about aspects not perceived by the senses, so it involves creating a teaching model based on creativity to prepare the student for change, making them learn to think $[13,31]$.

It is necessary to integrate the development of artistic thinking and design processes as an objective in university centers as a play of imagination and creativity. Consequently, the arts help students to develop creativity and, therefore, expressiveness, and the ability to familiarize to different situations in their lives [32-34]. Digital art is important for students to improve not only their performance in other subjects, such as mathematics, but rather, this discipline is taught because it is necessary to enable maximum personal development and learning between metacognition and meta-emotion [35,36].

Creativity allows you to learn and discover new options and experiences. This gives a slight idea that creativity should not be a special event, but common practice, a condition worked on daily [26]. Artistic creation can be transferred to other areas, so that curricula that promote creative thinking allow students to communicate, in addition to understanding, empathizing and seeing social problems from another point of view [34,37].

In this context, the irruption of ICT in education has led to the development of new methodological models by university teachers, such as visual thinking, with technology as the central axis, and that go hand in hand with the development of creativity. The use of technology has been a challenge for university teaching, but at the same time, it has favored giving prominence in learning to the student. Connecting virtual and mixed environments is new for teachers and students, granting great didactic benefits and everyday technological language to the classrooms [38-40].

The challenges imposed by the new digital scenario encourage reflecting on the possibilities of artistic education in a historical moment in which we combine face-to-face educational moments with online dislocations. Image technologies are one of our greatest allies. Within these technologies, the learning possibilities that augmented reality offers without leaving the classroom are recognized. It is a creative resource and a tool to guide creativity, offering the student the possibility to directly experience its stimuli, endowing learning with significant value $[39,41]$. HEIs are committed to the quality of education they offer, so digitization helps to focus the strategies to achieve it. Pixel art, 3D modeling, vector art and fractal art are some examples where digital technology is applied in the design and production process $[15,42]$. Likewise, the introduction of digital technology influences the acquisition of competences during the learning and teaching process.

Visual thinking is our ability to discover, generate, develop, manipulate, relate and share ideas in a fast and intuitive way. Visual thinking proposes different ways of apprehending the world based on the senses. In addition, it dignifies the importance of visual stimuli in perception and thought development $[10,43]$.

The significance of creative thinking among young university students lies in the fact that it includes the processes of divergence and convergence. Divergent thinking generates new thoughts, that is, it expands capabilities and ideas, makes new connections and opens areas to explore $[38,44]$. Creativity linked to learning provides a platform to increase the wellbeing of university students. In this context, students must experience resourcefulness first to understand how the process works. Therefore, it is challenging for HE to provide environments and opportunities to teach students these observation skills.

The incorporation of ICT into artistic teaching and visual culture represents a new way of working and learning, making it possible to develop new strategies in the educational processes $[17,23]$. New digital tools, such as video games, social networks or virtual reality, are not obstacles to the social wellbeing of students, but on the contrary, they allow us to communicate, entertain ourselves, play games and obtain information if their use is appropriate [45]. Therefore, through them, students can achieve an approach to the study 
of various disciplines with the help of visual tools, thus being able to understand, interpret and value artistic skills for their professional future $[7,46]$. The university learning space has a direct effect on academic motivation and the wellbeing of students.

\section{Data and Methods}

Bibliometric techniques have been applied to offer an approach to research related to digital design in artistic education in the context of HE. The bibliometric indicators obtained are tools that allow measuring scientific productions and analyzing the impact caused by scientific works in the community [47]. The objective of this methodology is to identify and analyze the main components within a specific research field. Likewise, it seeks to present the evolution of interest in the subject under study by reflecting the most relevant authors, countries, journals and keywords in recent years [48,49].

Its application is supported by the leading role played by documents in the propagation of new knowledge. Statistical data are not the limit of the function of the indicators of scientific activity, but rather, their use is as a tool to be integrated to obtain solid descriptions related to science. Using these techniques, it is possible to create, visualize and explore bibliographic maps [50,51]. In this study, links and documents form a joint bibliographic network. This methodology has been applied successfully in other studies [52-54].

An analysis of the scientific literature was carried out from the Scopus database. The search equation used included the following terms that combine the production of this research field: "higher education", "artistic", "digital" and "design". The motivation was to examine the subfields of "title, abstract and keywords" in the period 2000-2020, in the same way as in other bibliometric studies. The search was limited to the thematic area of "Arts and Humanities" in order not to distort the sample and to ensure that it only contains those related to the concept of art. Hence, the definitive sample contained 1027 articles, while the variables analyzed were year of publication, thematic area, journal, author, country of affiliation of the author, research institution to which the author is affiliated and keywords that describe the article.

This study used indicators of (i) activity, to offer data on the volume and impact of research activities; and (ii) relationship (structural collaboration), to track interactions between analysis elements $[55,56]$. The indicators for the analysis of scientific production were the distribution by years of the published articles and the productivity of the journals, authors, countries/territories and institutions.

To measure the connections established between the driving agents of this field of research, analysis of (i) co-authorship was applied, which provides a vision of the cooperation patterns between items [57]; and (ii) co-citation, which starts from the assumption that between two or more documents that are co-cited in a third work, there is a thematic similarity [58]. Meanwhile, to measure the connections established between the keywords that define the publications, a co-occurrence analysis was applied [48]. This method has allowed the detection of the main research topics carried out during the analyzed period (2000-2020).

VOSviewer software (version 1.6.15, Centre for Science and Technology Studies, Leiden University, Leiden, The Netherlands) was used for the mapping [59]. It allowed the processing of terms and the analysis of grouping, with the purpose of visualizing maps by co-authorship and co-occurrence. The links between items, from the indicators of collaboration structure, were analyzed using network maps due to their success in bibliometrics. VOSviewer showed the collaborative structure indicators, which measure the strength of relationships between authors, research institutions and countries/territories, as well as the identification of research trends based on the use of keywords [60,61].

\section{Results and Discussion}

\subsection{Growth of Scientific Activity}

Data on the temporal distribution of scientific production are of importance since they allow observing the flow of publications and the importance or depth that a topic 
is acquiring in research. Figure 1 shows the main results of the evolution over 21 years of scientific production in this field of research, that is, from 2000 to 2020. The year with the highest scientific production, according to Scopus, was 2020, with 182 articles; 159 were published in 2019; and 112 articles in 2007. A growing trend in production can be seen, from 2017 to 2020 (527 articles; 51.31\% of total), since educational researchers identify critical thinking, creativity and collaboration as crucial 21st-century competencies for a dynamic world. Art education is understood as a key element to develop an innovative mindset $[62,63]$.

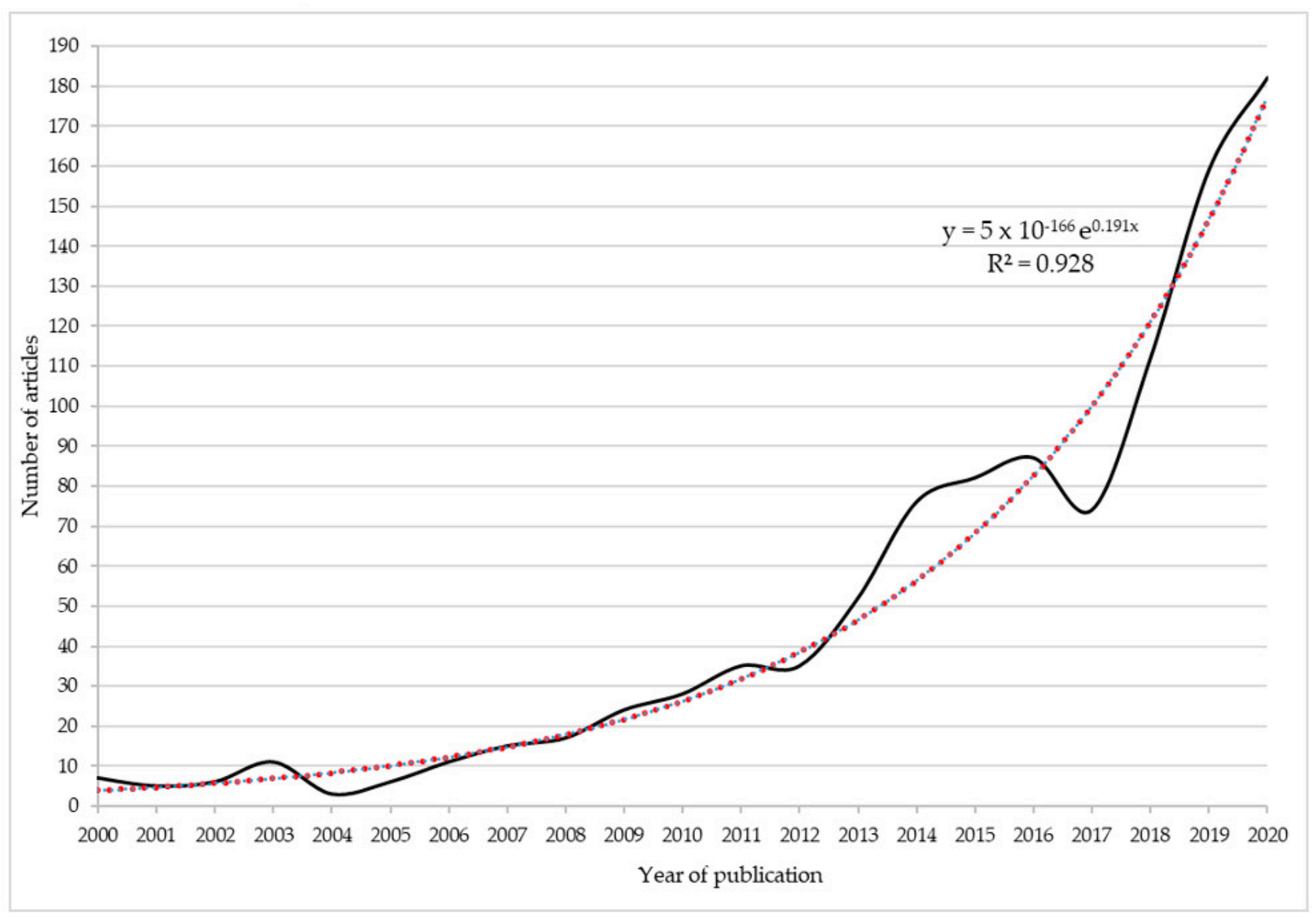

Figure 1. Evolution of the number of published articles (2000-2020).

During the analyzed period, it is observed that production has ups and downs, although its increasing trend is notorious. It is noteworthy that in the last decade (2011-2020), $87.05 \%$ of the articles (894) were published, while in the first 11 years (2000-2010), it was only $12.95 \%$. In this first sub-period, in no year did the number of articles published on this topic reach 30 . The results of this study are presented according to productivity, units of analysis and temporality and grouped into clusters, to respond to collaboration between journals, authors, countries and research institutions, in addition to keywords that define the articles.

The exponential trend line denotes that the volume of articles on this topic increases more rapidly over time during the period 2000-2020 (see Figure 1, red line). This trend shows the fit of the model with a coefficient of determination $\left(\mathrm{R}^{2}\right)$ of 0.928 , which refers to the proportion of the variance in the dependent variable (number of articles), which is predictable from the independent variable (year of publication).

The 1027 articles identified were published in 19 different languages. It is significant to highlight the supremacy of English in the language of publications $(895 ; 87.15 \%)$, followed by Spanish $(70 ; 6.82 \%)$. None of the other languages reached $1 \%$ of the total. 
The articles were published in 333 different journals. Research on digital design in arts education in the field of $\mathrm{HE}$ attracted a growing number of journals and authors during this period, as evidenced by the growth in the number of published documents and the breadth of interested journals [42]. Most of the scientific production worldwide is concentrated in the most universal language used by high-impact journals, which is English. In this way, the results obtain greater diffusion and acceptance in the scientific community. Likewise, the institutions of Anglo-Saxon countries, for the most part, have resources, funds and budgetary allocations destined for the publication, research and development of R\&D projects, making their results more visible and relevant worldwide [64].

According to the Scopus database, the top 10 journals with the most published articles were International Journal of Art and Design Education, with 62, Computers in Human Behavior (40), Mediterranean Journal of Social Sciences (38), Art Design and Communication in Higher Education (30), Opcion (26), Library Philosophy and Practice (25), Sage Open (22), International Journal of Innovation Creativity and Change (21), Perspektivy Nauki I Obrazovania (21) and Arts and Humanities in Higher Education (19).

Figure 2 displays the network map of the journals that are published at an international level on digital design in art education, based on co-citation analysis. The lines between the elements represent links. The distance between two nodes on the map indicates the relationship of the journals in terms of citation links. The journals are associated in five clusters. For each of the clusters, the following are indicated: the color that represents it, the percentage of elements that make it up over the total and the links and citations of each of the top five journals.

- Cluster 1 (pink, 28\%): Higher Education (65 links, 114 citations), Journal of Educational Psychology (52, 78), Assessment E Evaluation in Higher Education (56, 61), Review of Educational Research $(63,61)$ and Educational Researcher $(56,55)$.

- $\quad$ Cluster 2 (green, 26\%): Tesol Quarterly (53, 86), System (52, 70), Applied Linguistics $(51,57)$, English for Specific Purposes $(38,51)$ and Journal of English for Academic Purposes $(42,51)$.

- Cluster 3 (red, 22\%): Studies in Higher Education (68, 155), Design Studies (29, 92), Teaching in Higher Education $(56,71)$, International Journal of Art $\mathcal{E}$ Design Education $(31,60)$ and Art, Design $\mathcal{E}$ Communication in Higher Education $(29,53)$.

- Cluster 4 (yellow, 20\%): Computers E Education $(58,202)$, Computers in Human Behavior $(47,147)$, British Journal of Educational Technology $(56,77)$, Journal of Computer Assisted Learning $(54,57)$ and Communication Education $(34,44)$.

- $\quad$ Cluster 5 (purple, 4\%): British Journal of Music Education (15, 40), Music Education Research $(12,35)$ and Psychology of Music $(11,30)$.

The visualization of the map shows a high co-citation, which shows the direct links between journals in the investigation of the topics covered. This map contributes to understanding and tracking the nature of research on digital art in artistic education at the university, with the centrality of journals such as Higher Education, Computers $\mathcal{E}$ Education, Studies in Higher Education and Design Studies. 


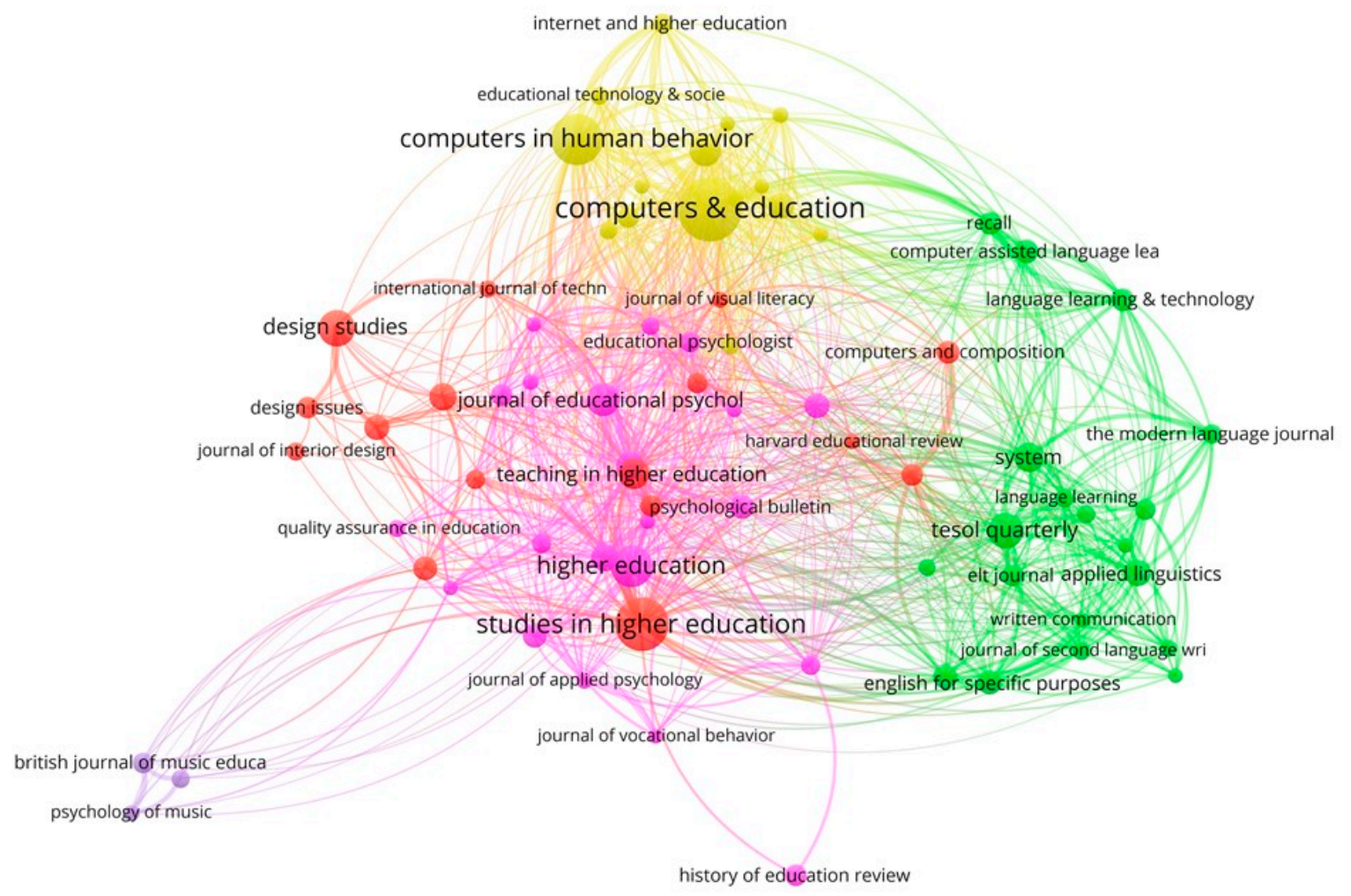

Figure 2. Network of journals based on co-citation analysis (2000-2020).

\subsection{Outputs of Driving Agents}

At an international level, 2120 authors published the total number of articles that make up the sample. According to Scopus, among the 10 authors with the most publications, Oliver, E. (University of South Africa, Pretoria, South Africa) stands out, who develops themes related to digital education applied to another area of knowledge.

Taking into account the subject of digital design and art education, we consider the authors Budge, K.(University of Western Sydney, School of Humanities and Communication Arts, Penrith, Australia); Himonides, E. (UCL Institute of Education, London, United Kingdom (UK)); Jandrić, P. (University of Wolver-Hampton, Wolverhampton, UK; and University of Zagreb, Zagreb, Croatia); Marshalsey, L. (Griffith University, Queensland College of Art, Brisbane, Australia); Muhuro, P. (University of Fort Hare, Center for Teaching and Learning, Alice, South Africa); Ntlabathi, S. (University of Fort Hare, Alice, South Africa); Sclater, M. (Glasgow School of Art, Glasgow, UK); Serradell-López, E. (Universitat Oberta de Catalunya, Barcelona, Spain); and Welch, G. (UCL Institute of Education, Department of Culture, Communication and Media, London, UK). All of them have three publications each, and the topics they address are related to art, design and creativity in HE and the pedagogical use of visual feedback to improve learning dynamics, among others.

Figure 3 shows the collaborative network based on the co-citation method among authors who published on the subject between 2000 and 2020. The colors represent the groups that form the units of work in the scientific publication, while the diameter of the circumference depends on the number of articles published by each author. The top authors are grouped into four clusters. 


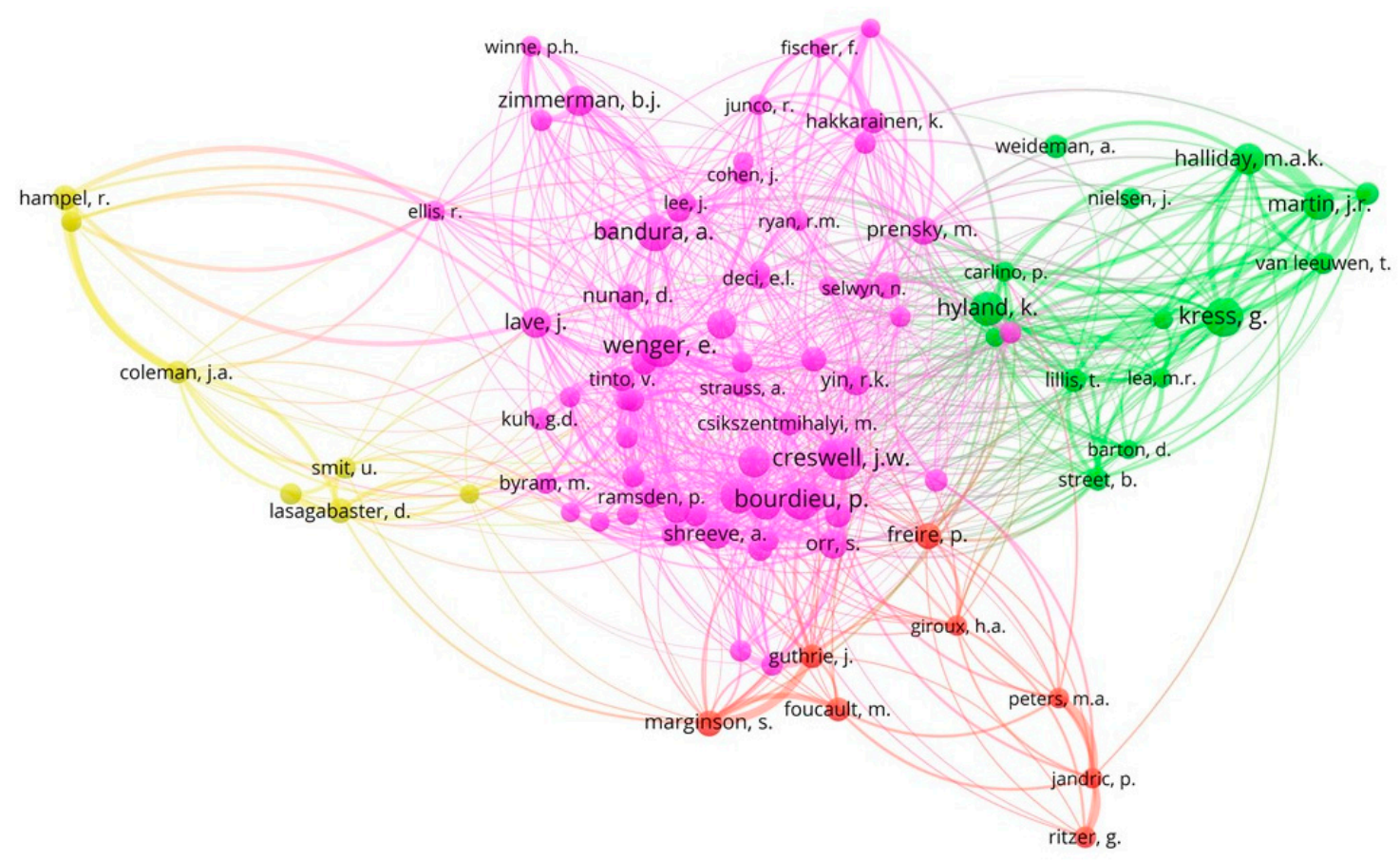

Figure 3. Network of authors based on co-citation analysis (2000-2020).

- Cluster 1 (pink, 68\%): Wenger, E. (63 links; 60 citations); Creswell, J.W. (53; 59); Bourdieu, P. (50; 52); Bandura, A. (32; 49); and Biggs, J. (54; 45).

- $\quad$ Cluster 2 (green, 16\%): Kress, G. (35; 52); Hyland, K. (32; 44); Martin, J.R. (18; 38); Halliday, M.A.K. (26; 37); and Lillis, T. (25; 24).

- $\quad$ Cluster 3 (red, 9\%): Marginson, S. (22; 28); Freire, P. (38; 27); Foucault, M. (22; 24); Guthrie, J. (19; 23); and Ritzer, G. (7; 20).

- $\quad$ Cluster 4 (yellow, 7\%): Hampel, R. (4; 26); Lasagabaster, D. (15; 26); Coleman, J.A. (16; 22); Marsh, D. (9; 20); and Smit, U. (14; 20).

Clustering based on co-citation indicates a wide variety, which promotes the link between arts education and creativity. Cluster 1 is the largest and the one that generates the most activity among its members, with Wenger, E.; Creswell, J.W.; and Bourdieu, P., among the most prominent.

In relation to the critical discourse proposed by some of the authors that make up the clusters, such as Freire, P. or Foucault, M., it could be mentioned that, at present, the new generations are continuously bombarded with new ICT that promote personal success above all things, increasingly raised in a context led by globalized capitalism, along with a certain form of hedonism as well as political conformism. In this sense, Freire, P. and Foucault, M. could be the standard bearers of this neoliberal ideology [28,65]. These digital tools are the vehicle par excellence to carry the new neoliberal, individualist ideology, unconcerned about the social. It is the new generations, the so-called digital natives, who make ICT an obligatory part of their daily lives, being the ones who are most affected by all this [66].

It is worth mentioning that the purpose of this research was to seek the proper use of digital technologies and in this case focused on artistic education attending to a new mode of expression and global exchange, capable of also being a powerful discursive tool in addition to being creative and cultural [23].

At an international level, 1546 research institutions published the total number of articles that make up the sample. Regarding the affiliations of the authors driving this research, Table 1 shows the 10 most productive research institutions on digital design in artistic education in the context of HE, during the period examined. University of South Africa, University of Melbourne, and North-West University stand out in the first place, 
with 10 articles, followed by the Universidad de Granada, and The Glasgow School of Art, with 9 articles. It is remarkable that seven of the ten most productive institutions contributed to the research topic in 2020, which confirms the interest in this topic. This also enhances the growth of this field of research, since numerous institutions have since begun to contribute articles on arts education and creativity and their link with university training and education.

Table 1. Main research institutions (2000-2020).

\begin{tabular}{ccccc}
\hline Research Institution & City, Country & Articles * & 1st A * & Last A * \\
\hline University of South Africa & Gauteng, South Africa & 10 & 2009 & 2019 \\
University of Melbourne & Victoria, Australia & 10 & 2011 & 2020 \\
North-West University & North West, South Africa & 10 & 2009 & 2020 \\
Universidad de Granada & Granada, Spain & 9 & 2008 & 2020 \\
The Glasgow School of Art & Glasgow, UK & 9 & 2013 & 2020 \\
Universidad Jaume I & Barcelona, Spain & 8 & 2012 & 2020 \\
Universiti Teknologi MARA & Shah Alam, Malaysia & 8 & 2014 & 2019 \\
RMIT University & Melbourne, Australia & 8 & 2005 & 2020 \\
Universiti Kebangsaan & Bangi, Malaysia & 7 & 2013 & 2020 \\
Malaysia & Alice, South Africa & 7 & 2014 & 2014 \\
University of Fort Hare &
\end{tabular}

1st A: First article; Last A: Last article; $\left(^{*}\right)$ in this research topic.

At the international level, 80 countries/territories published the total number of articles that make up the sample. According to Scopus, the 10 most prolific countries/territories were the United States (US), with 167 articles published, representing $16.26 \%$ of the total; the UK (160, 15.58\%); Spain (106, 10.32\%); Australia (82, 7.98\%); South Africa (61, 5.94\%); the Russian Federation (50, 4.87\%); Malaysia (37, 3.60\%); Indonesia (31, 3.02\%); China (24, $2.34 \%)$; and Turkey $(22,2.14 \%)$.

Figure 4 shows the map of collaboration between the main countries based on the co-citation method. The countries were gathered into four clusters.

- Cluster 1 (pink, 38\%): Turkey (3 links; 214 citations), Sweden (1; 211), Hong Kong $(2 ; 205)$, Saudi Arabia $(5 ; 39)$ and New Zealand $(6 ; 34)$.

- Cluster 2 (green, 33\%): The US (7; 1202), the UK (22; 838), South Africa (2; 85), Canada $(1 ; 91)$ and Finland $(2 ; 84)$.

- Cluster 3 (red, 19\%): Australia (8;438), China $(2 ; 44)$, Netherlands $(1 ; 440)$ and Taiwan $(2 ; 37)$.

- Cluster 4 (yellow, 10\%): Norway $(3 ; 37)$ and France $(1 ; 13)$.

The results obtained based on the co-citation between countries show the evolution in this topic, establishing the correlation between pedagogy and the process of learning art design through digital tools $[67,68]$. Likewise, the mobility of students and teachers between countries represents the opportunity to link art and design as a tool to develop creativity, through creative thinking as a transversal skill. Digital resources and arts education can develop research and practices to cultivate creative education in all students. Young people who are in an educational system that promotes creative and critical thinking will have added value in various daily contexts. Art must be transversal to all areas of knowledge and constitute a transversal axis of society. These findings are related to the integration of arts education, ICT and ethics in transversal competences promoted by the national educational systems $[69,70]$. 


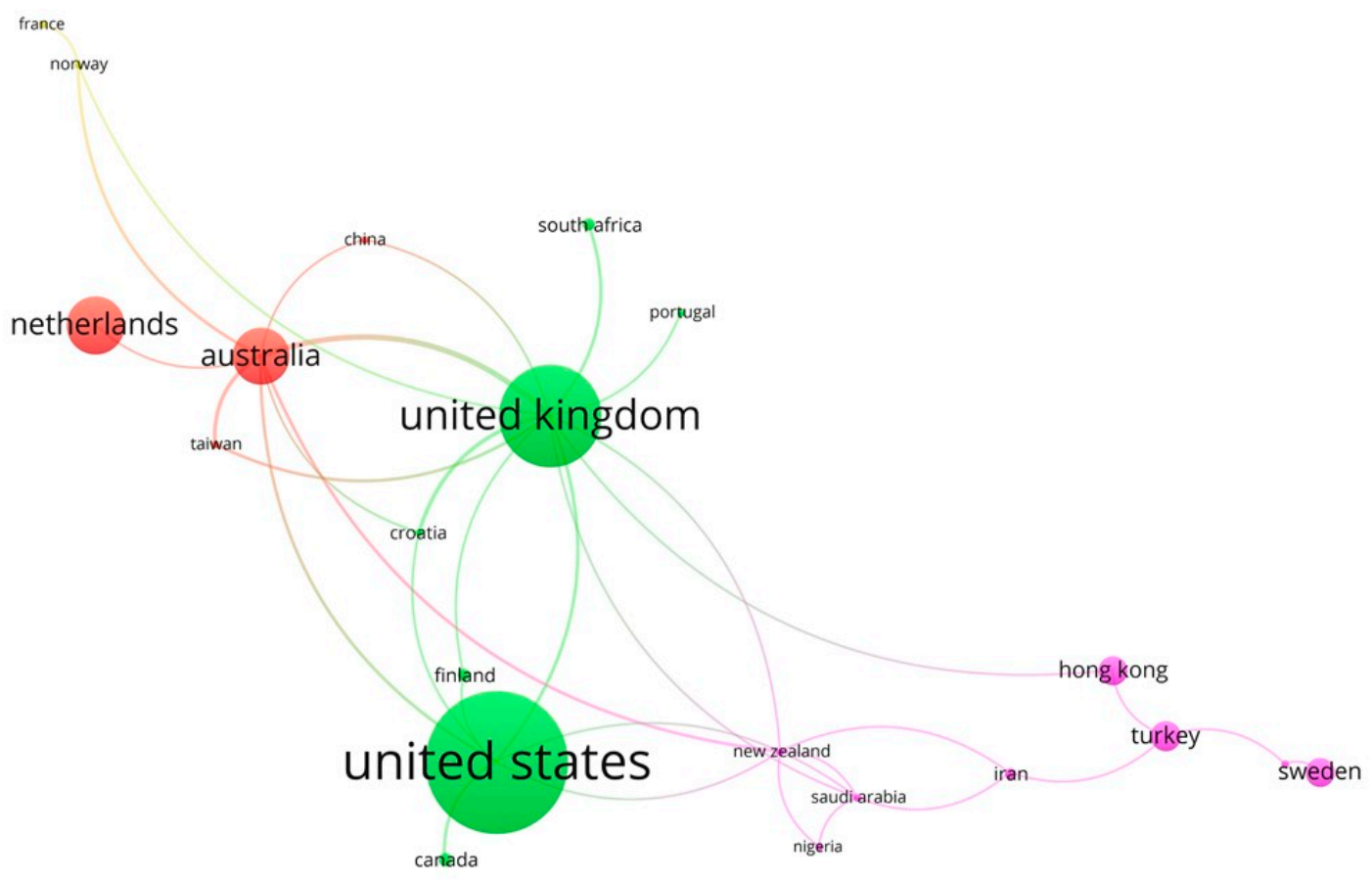

Figure 4. Network of countries/territories based on co-citation analysis (2000-2020).

\subsection{Analysis of Keywords}

Figure 5 shows the network map for the keywords of the research articles on digital design in artistic education, during the 2000-2020 period. The color of the nodes is used to differentiate the clusters based on the number of co-occurrences, and their size varies according to the number of repetitions. Furthermore, some lines of research developed by the different communities were identified. Six main lines of research are distinguished, which are grouped under the terms "Art", "Level", "Formation", "Faculty", "Perception" and "Relationship". It is convenient to clarify that cluster 2, whose heading term is level, is related to artistic creation; it has a technique or a set of its own techniques that, depending on the domain of the author, will lead to the result having one level or another.

- Cluster 1 (pink, 25\%): art (links: 349, total link strength: 2814, occurrences: 241), school $(344,2394,136)$, resource $(332,1740,108)$, design education $(201,791,69)$, creativity $(187,984,67)$ and reading $(165,541,64)$.

- $\quad$ Cluster 2 (green, 19\%): level $(487,7007,323)$, effect $(339,2433,138)$, difference $(315,1677,94)$, influence $(298,1127,73)$ and scale $(213,2426,61)$.

- Cluster 3 (red, $17 \%)$ : Formation $(208,1149,68)$, orientation $(148,456,31)$, educational process $(109,348,23)$, simulation $(44,141,22)$ and distance education $(43,287,13)$.

- Cluster 4 (yellow, $17 \%$ ): faculty $(291,2663,109)$, lecturer $(272,2145,100)$, innovation $(240,1198,66)$, collaboration $(187,816,47)$, scholar $(152,493,27)$ and instructional design $(98,261,15)$.

- Cluster 5 (purple, 12\%): perception $(350,2888,136)$, research design $(279,1223$, $64)$, metaphor $(66,1915,29)$, students' perception $(155,533,26)$ and academic year $(175,637,18)$.

- Cluster 6 (cian, 10\%): relationship (211, 2976, 152), effect (210, 2751, 147), faculty $(190,2728,109)$, society $(198,1565,87)$ and dimension $(153,2092,53)$. 


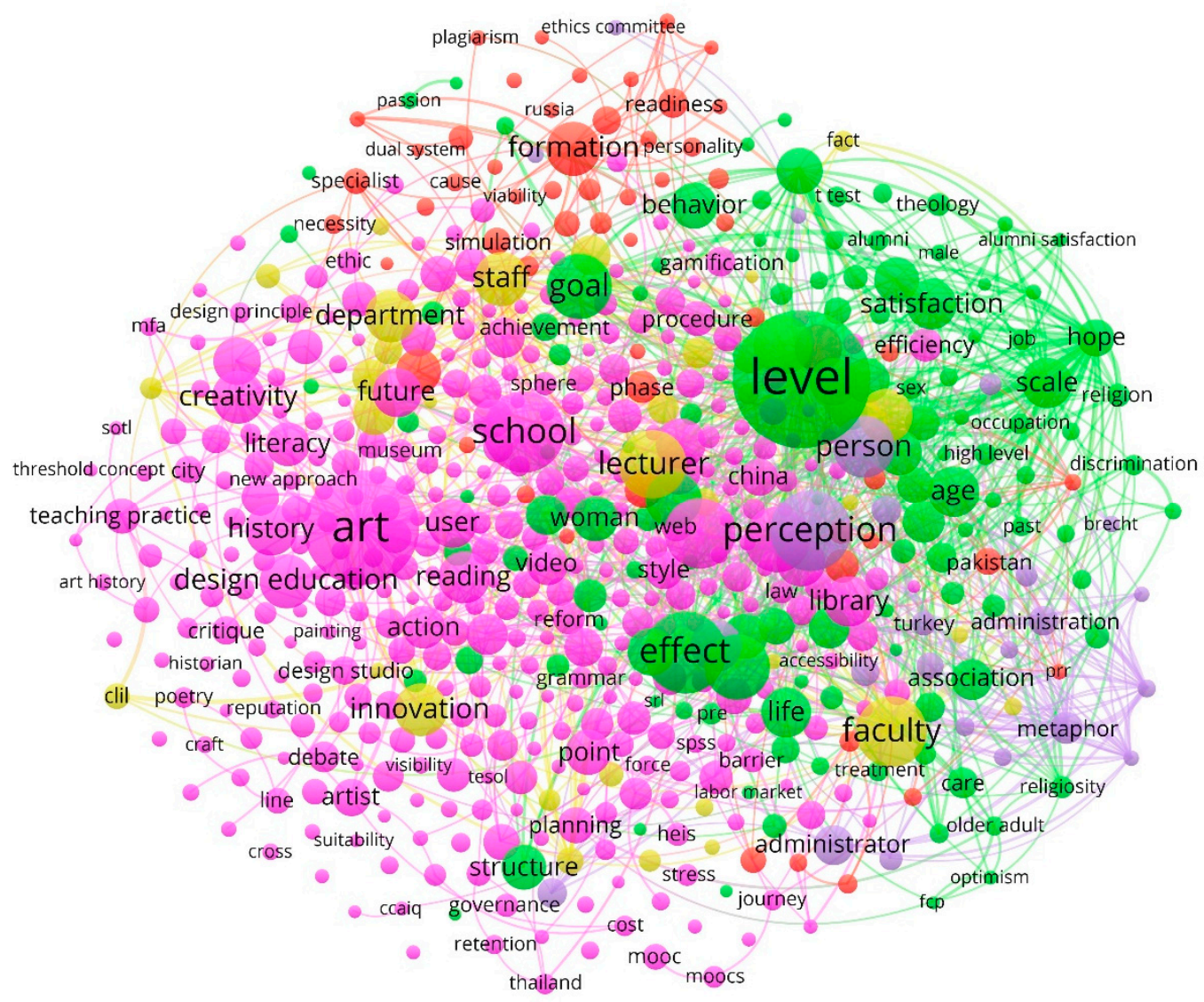

Figure 5. Network of keywords based on co-occurrence method (2000-2020).

These schools of thought link the concepts studied in the thematic of digital design in artistic education. This includes aspects related to the use of technologies in artistic education. In this analysis of the keywords, it was observed that the terms artistic education, technology, creativity, digital art, learning, ICT education, and pedagogy are the most representative. The research with the largest volume on this subject studied the attributes of new technologies at the service of pedagogies that promote the development of creative thinking, in addition to problem-solving and decision-making skills, as key elements for the development of creativity [71,72].

The mentioned keywords arise in relation to demonstrating the contribution that art makes to the formation of the human mind. Recognizing the value of art in the educational process allows us to recognize perception as a cognitive fact $[18,21]$, reminding us that the creation of images in any medium, be it visual, auditory, verbal, etc., requires invention and imagination. The emergence of these terms is related to the need to adapt to the changing scenario that is presented to us today, having to respond not only cognitively to problems but also in a sensitive and creative way [73].

This is related to research that assesses and describes creativity as a necessary skill for 21st-century students in HE, and the positive effects it has on student motivation. This is consistent with studies reviewed in the literature, which demonstrate how the arts help students to develop creativity and, therefore, flexibility, expressiveness and adaptability to different situations $[74,75]$. There is evidence that learning the arts is an emotional discipline that requires reflection and intellectual rigor. The results show what has been identified by other research so that the value that creativity and innovation brings is in its ability to develop effective technological solutions to the problems stimulated by change $[30,76]$.

Studies that correspond to the importance of generating digital literacy in university students and which understand digital literacy not only as a medium but also as a new 
form of communication and the creation and understanding of information are of interest. At present, there is a growing need for the development of aesthetic thinking [41,77]. In the current socioeconomic context, the training of professionals with strategic capacity is essential. The dynamics of the labor market, the unstoppable technological change, interculturality in the professional and educational field and the predominant scheme of thought, which favors immediacy in a framework of liquid modernity, make it necessary to modify the profile of next artists, privileging the development of critical analysis, strategic knowledge and creativity [78].

Advocating for visual culture in virtual worlds is neither purely authentic nor purely imaginative. When culture emerges in a visualized virtual world, where everything that can be seen is created by its users, visual culture can be diverse and complex. Users of different cultural origins perceive and construct meanings that may be different from those intended by the creators of the virtual world and other users [79].

Figure 6 shows the development of each conglomerate according to the period in which they emerged and their evolution during the period 2000-2020. This analysis allows us to understand the importance of the keywords based on the time in which they appeared in the research, because the most pioneering concepts will have the greatest influence and will be a reference for those that emerged later.

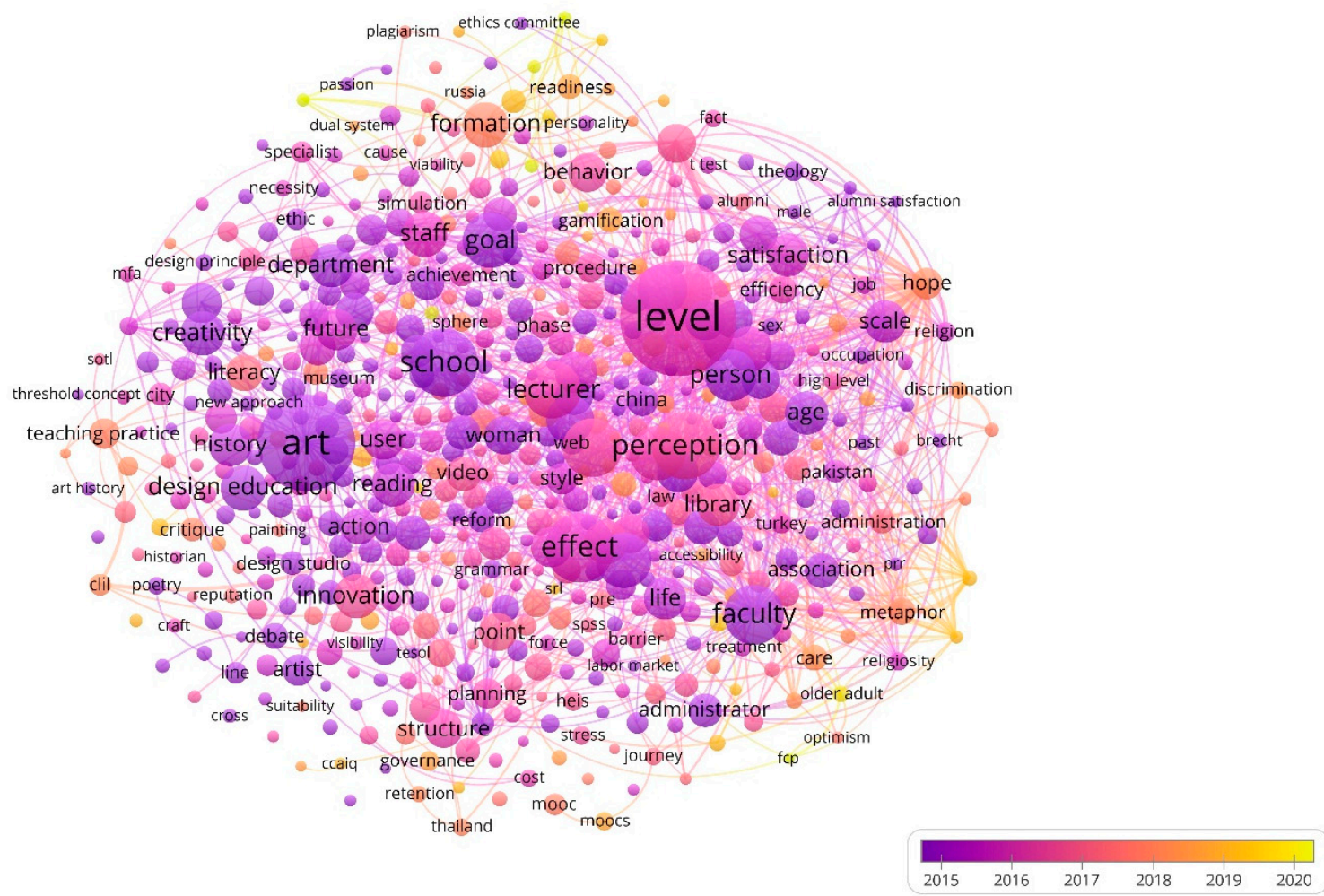

Figure 6. Evolution of key-terms based on the co-occurrence method (2000-2020).

The presence of six differentiated clusters allows us to deduce how the implications of digital design in artistic education in the context of HE include different lines of study in research activity-artistic, social and technological $[71,80,81]$. HEIs are making great efforts to include new technologies in various areas, especially those related to culture and art. Sometimes, these efforts are not reflected in the campuses, and this activity acts as a background to provide new tools in research. ICT in classrooms have allowed students technological resources to stimulate their curiosity to access information in a visual and creative way. Likewise, the inclusion of both divergent and convergent thinking with digital methodologies in arts education is a challenge in higher education when it comes to offering environments where artistic creations are impregnated with creativity and 
inventiveness, supported by an educational system involved in the qualities of student development $[38,82]$.

\section{Conclusions}

The aim was to examine the evolution of scientific research at the international level, in the period 2000-2020, on digital design in artistic education in the university context. Bibliometric techniques were applied to 1027 articles extracted from the Scopus database. The journals where the articles were published, the authors, the research institutions and the most productive countries/territories at the international level were studied. Moreover, the main current research lines were identified.

Publication has increased particularly in the last triennium (2018-2020), since 527 articles $(51.31 \%)$ were published, thus confirming the current relevance of this research topic at a global level. This is especially due to the ease of access to and availability of new technological tools and the demand of the art market itself. The most productive journal was the International Journal of Art and Design Education, with 62 articles published. The authors who have published the most on this subject wereBudge, K.; Himonides, E.; Jandrić, P.; and Marshalsey, L., among others, and the University of South Africa the most prolific institution. The most productive countries in this area of research are the United States, the United Kingdom and Spain.

The current lines of research studied were detected: art, level, training, faculty and perception and relationship. These mainly focused on analyzing digital environments and the possibilities of enhancing creativity in university learning contexts. Considering the current socioeconomic context, the training of professionals with strategic and creative capacity is essential. The dynamics of the labor market, the unstoppable technological change, interculturality in the professional and educational field and the predominant scheme of thought, which favors immediacy in a framework of liquid modernity, make it necessary to enhance the profile of next artists, privileging the development of critical analysis, strategic knowledge, and creativity. In this sense, the literature produced has highlighted, in general terms, the importance of creativity, aesthetic and divergent thinking to respond to the changes imposed by the current world.

Future lines of research, depending on the advancement of terminology, should be in areas such as 3D virtual reality, robotics, 3D modeling, airbrushing, pixel art, typographic art, vector art, generative art, net art or digital sculpture. The multidisciplinary nature of the subject means it can be extended to areas such as architecture, mathematics, engineering, advertising, marketing, psychology or university training and graduate teaching staff.

The results obtained are useful for academics, HEI managers and other interest groups, since scientific activity in this field has been evaluated. The limitations found in this study can serve as the basis for future research, such as the fact that (i) some authors publish few articles, but they are highly relevant in a thematic area; (ii) bibliometric techniques could be combined with other qualitative ones; and (iii) research results can be increased by using documents from other databases.

This research adds to the active role that educational activities must play in relation to the arts, since its implementation affects the entire society. Thereby, it is key to understand that emotions and creative abilities are the basis of the ability of students to persist in the activities they carry out with a goal and performance orientation.

Author Contributions: Conceptualization, methodology, software, validation, formal analysis, investigation, data curation, writing — original draft preparation, writing — review and editing, visualization, supervision, E.A.-S. and M.-D.G.-Z.; project administration, M.-D.G.-Z.; resources, E.A.-S. Both authors have read and agreed to the published version of the manuscript.

Funding: This research received no external funding.

Institutional Review Board Statement: Not applicable.

Informed Consent Statement: Not applicable. 
Data Availability Statement: The data were obtained from Elsevier's Scopus database (https:// www.scopus.com/) accessed on 18 February 2021.

Acknowledgments: This study is the result of research carried out at the Rey Juan Carlos University of Madrid (Spain).

Conflicts of Interest: The authors declare no conflict of interest.

\section{References}

1. Meseguer-Sánchez, V.; Abad-Segura, E.; Belmonte-Ureña, L.J.; Molina-Moreno, V. Examining the research evolution on the socio-economic and environmental dimensions on university social responsibility. Int. J. Environ. Res. Public Health 2020, 17, 4729. [CrossRef]

2. Heggen, C.; Sridharan, V.G.; Subramaniam, N. To the letter vs the spirit: A case analysis of contrasting environmental management responses. Account. Audit. Account. J. 2018, 31, 478-502. [CrossRef]

3. Donnelly, R.; Maguire, T. Building digital capacity for higher education teachers: Recognising professional development through a national peer triad digital badge ecosystem. Eur. J. Open Distance E-Learn. 2021, 23, 1-19. [CrossRef]

4. Immordino-Yang, M.H.; Damasio, A. We feel, therefore we learn: The relevance of affective and social neuroscience to education. LEARNing Landsc. 2011, 5, 115-131. [CrossRef]

5. Michael, J.A.; Eisner, E.W. Educating artistic vision. Art Educ. 1973, 26, 28. [CrossRef]

6. Garcia-Esteban, S.; Jahnke, S. Skills in european higher education mobility programmes: Outlining a conceptual framework. High. Educ. Ski. Work-Based Learn. 2020, 10, 519-539. [CrossRef]

7. Gale, C. Art school as a transformative locus for risk in an age of uncertainty. Art Des. Commun. High. Educ. 2020, 19, 107-118. [CrossRef]

8. Lombaerts, K.; De Mette, T.; Buffel, T. Creativity in artistic education: Introducing artists into primary schools. Int. J. Art Des. Educ. 2012, 31, 53-66. [CrossRef]

9. Pratsri, S.; Nilsook, P. Design on big data platform-based in higher education institute. High. Educ. Stud. 2020, 10, 36. [CrossRef]

10. Hsiao, C.-Y. Enhancing children's artistic and creative thinking and drawing performance through appreciating picture books. Int. J. Art Des. Educ. 2010, 29, 143-152. [CrossRef]

11. Xue, X.; Wang, L.; Yang, R.J. Exploring the science of resilience: Critical review and bibliometric analysis. Nat. Hazards 2018, 90, 477-510. [CrossRef]

12. Islam, M.A.; Agarwal, N.K. What is the impact of library and information science on knowledge management research? VINE J. Inf. Knowl. Manag. Syst. 2020, 51, 1-26. [CrossRef]

13. Codd, J.A. Interpretive cognition and the education of artistic appreciation. J. Aesthetic Educ. 1982, 16, 15. [CrossRef]

14. Burkhart, R.C. Emotion and imagination in pottery. Art Educ. 1962, 15, 7-9. [CrossRef]

15. Serkova, V. The digital reality: Artistic choice. IOP Conf. Ser. Mater. Sci. Eng. 2020, 940, 012154. [CrossRef]

16. Kraehe, A.M. Art and the mind. Art Educ. 2020, 73, 4-7. [CrossRef]

17. Paşca, E.M. History and Modernity in Artistic Education from Romania. Rev. Artist. Educ. 2019, 18, 347-352. [CrossRef]

18. Douglas, A.; Coessens, K. Experiential knowledge and improvisation: Variations on movement, motion, emotion. Art Des. Commun. High. Educ. 2012, 10, 179-198. [CrossRef]

19. Katayama, N.; Baba, Y.G. Measuring artistic inspiration drawn from ecosystems and biodiversity: A case study of old children's songs in Japan. Ecosyst. Serv. 2020, 43, 101116. [CrossRef]

20. Abad-Segura, E.; de la Fuente, A.B.; González-Zamar, M.D.; Belmonte-Ureña, L.J. Effects of circular economy policies on the environment and sustainable growth: Worldwide research. Sustainability 2020, 12, 5792. [CrossRef]

21. Liu, X. Artistic reflection on artificial intelligence digital painting. J. Phys. Conf. Ser. 2020, 1648, 032125. [CrossRef]

22. Hasenhütl, G. Manual drawing in transformation: A brief assessment of "design-by-drawing" and potentials of a body technique in times of digitalization. J. Aesthetic Educ. 2020, 54, 56-74. [CrossRef]

23. Bukharova, E.; Urozhenko, O. Artistic reality in the space of digital technologies: Towards the problem of art criticism. Quest. Expertise Cult. Arts Des. 2020, 9-14. [CrossRef]

24. Schoute, M. The relationship between product diversity, usage of advanced manufacturing technologies and activity-based costing adoption. Br. Account. Rev. 2011, 43, 120-134. [CrossRef]

25. Sponem, S.; Lambert, C. Exploring differences in budget characteristics, roles and satisfaction: A configurational approach. Manag. Account. Res. 2016, 30, 47-61. [CrossRef]

26. Arbuz-Spatari, O. Art-Subject-Object in artistic and plastic creativity of pupils and students in artistic education. Rev. Artist. Educ. 2019, 18, 233-240. [CrossRef]

27. Kaplan, F.F. Drawing assessment and artistic skill. Arts Psychother. 1991, 18, 347-352. [CrossRef]

28. McAvoy, M. Theater arts, global education, and policy; or, what chance the rapper taught us about arts education. Arts Educ. Policy Rev. 2020, 121, 98-105. [CrossRef]

29. Maeda, J. Design education in the post-digital age. Des. Manag. Rev. 2020, 31, 41-48. [CrossRef]

30. Chen, Q.; Beaty, R.E.; Qiu, J. Mapping the artistic brain: Common and distinct neural activations associated with musical, drawing, and literary creativity. Hum. Brain Mapp. 2020, 41, 3403-3419. [CrossRef] 
31. Mason, R. Reflection on visual art education and learning through art. SEA ART Educ. VISUAL J. Mak./Teach. ART Differ. 2020, 84-90. [CrossRef]

32. Richardson, J. The artistic current of competency-based education. J. Competency-Based Educ. 2016, 1, 60-61. [CrossRef]

33. Boguszewska, A. About visual education in the context of artistic illustration: Historical and contemporary aspect. Probl. Opiekuńczo-Wychowawcze 2020, 587, 14-23. [CrossRef]

34. Michael, M.K. Repositioning artistic practices: A sociomaterial view. Stud. Contin. Educ. 2019, 41, 277-292. [CrossRef]

35. Barwell, I. How does art express emotion? J. Aesthetics Art Crit. 1986, 45, 175. [CrossRef]

36. Hellman, D.S.; Milling, S. Social emotional learning in arts teacher education policy: A content analysis of assurance standards and course descriptions. Arts Educ. Policy Rev. 2020, 1-11. [CrossRef]

37. Cowan, D.A. Artistic undertones of humanistic leadership education. J. Manag. Educ. 2007, 31, 156-180. [CrossRef]

38. Haroutounian, J. Artistic ways of knowing in gifted education: Encouraging every student to think like an artist. Roeper Rev. 2017, 39, 44-58. [CrossRef]

39. Elwell, J.S. Religion and the digital arts. Brill Res. Perspect. Relig. Arts 2020, 4, 1-109. [CrossRef]

40. Fleischmann, K. Hands-on versus virtual: Reshaping the design classroom with blended learning. Arts Humanit. High. Educ. 2021, 20, 87-112. [CrossRef]

41. Abad-Segura, E.; González-Zamar, M.D.; Luque-de la Rosa, A.; Cevallos, M.B.M. Sustainability of educational technologies: An approach to augmented reality research. Sustainability 2020, 12, 4091. [CrossRef]

42. Inwood, H.; Kennedy, A. Conceptualising art education as environmental activism in preservice teacher education. Int. J. Art Des. Educ. 2020, 39, 585-599. [CrossRef]

43. Penketh, C. Towards a vital pedagogy: Learning from anti-ableist practice in art education. Int. J. Educ. Art 2020, 16, 13-27. [CrossRef]

44. Cross, N.; Holden, G. Design education in the open. Open Arts J. 2020, 1, 149-161. [CrossRef]

45. Alipour, L. Educating relational thinking to improve design creativity. Art Des. Commun. High. Educ. 2020, 19, 81-106. [CrossRef]

46. Perold-Bull, K. Becoming designer/researcher/teacher: Working towards decolonization of/through design in South African higher education. Art Des. Commun. High. Educ. 2020, 19, 131-148. [CrossRef]

47. Nederhof, A.J.; Zwaan, R.A.; De Bruin, R.E.; Dekker, P.J. Assessing the usefulness of bibliometric indicators for the humanities and the social and beha vioural sciences: A comparative study. Scientometrics 1989, 15, 423-435. [CrossRef]

48. Xie, L.; Chen, Z.; Wang, H.; Zheng, C.; Jiang, J. Bibliometric and visualized analysis of scientific publications on atlantoaxial spine surgery based on web of science and VOSviewer. World Neurosurg. 2020, 137, 435-442.e4. [CrossRef]

49. van Raan, A.F.J. Little... and beyond. Scientometrics 1994, 30, 529-531. [CrossRef]

50. Szomszor, M.; Adams, J.; Fry, R.; Gebert, C.; Pendlebury, D.A.; Potter, R.W.K.; Rogers, G. Interpreting bibliometric data. Front. Res. Metr. Anal. 2021, 5, 30. [CrossRef]

51. Little, R.J.A. A test of missing completely at random for multivariate data with missing values. J. Am. Stat. Assoc. 1988, 83, 1198-1202. [CrossRef]

52. Abad-Segura, E.; González-Zamar, M.-D. Effects of financial education and financial literacy on creative entrepreneurship: A worldwide research. Educ. Sci. 2019, 9, 238. [CrossRef]

53. López-Meneses, E.; Vázquez-Cano, E.; González-Zamar, M.-D.; Abad-Segura, E. Socioeconomic effects in cyberbullying: Global research trends in the educational context. Int. J. Environ. Res. Public Health 2020, 17, 4369. [CrossRef] [PubMed]

54. González-Zamar, M.D.; Abad-Segura, E.; Vázquez-Cano, E.; López-Meneses, E. IoT technology applications-based smart cities: Research analysis. Electronics 2020, 9, 1246. [CrossRef]

55. Haeffner-Cavaillon, N.; Graillot-Gak, C. The use of bibliometric indicators to help peer-review assessment. Arch. Immunol. Ther Exp. 2009, 57, 33-38. [CrossRef] [PubMed]

56. Aksnes, D.W.; Taxt, R.E. Peer reviews and bibliometric indicators: A comparative study at a norwegian university. Res. Eval. 2004, 13, 33-41. [CrossRef]

57. Wooding, S.; Wilcox-Jay, K.; Lewison, G.; Grant, J. Co-author inclusion: A novel recursive algorithmic method for dealingwith homonyms in bibliometric analysis. Scientometrics 2006, 66, 11-21. [CrossRef]

58. Walter, C.; Ribière, V. A citation and co-citation analysis of 10 years of KM theory and practices. Knowl. Manag. Res. Pract. 2013, 11, 221-229. [CrossRef]

59. Van Eck, N.J.; Waltman, L. Software survey: VOSviewer, a computer program for bibliometric mapping. Scientometrics 2010, 84, 523-538. [CrossRef]

60. Van Eck, N.J.; Waltman, L. Citation-based clustering of publications using CitNetExplorer and VOSviewer. Scientometrics 2017, 111, 1053-1070. [CrossRef] [PubMed]

61. Van Eck, N.J.; Waltman, L.; Noyons, E.C.M.; Buter, R.K. Automatic term identification for bibliometric mapping. Scientometrics 2010, 82, 581-596. [CrossRef]

62. Joshi, M.; Alavaikko, M. Service design approaches and applications in higher education: A thematic literature review. Art Des. Commun. High. Educ. 2020, 19, 241-255. [CrossRef]

63. Rutherford, S. Using desirable difficulty concepts to enhance durable learning in design education. Art Des. Commun. High. Educ. 2020, 19, 65-79. [CrossRef] 
64. Albarillo, F. Language in social science databases: English versus non-english articles in JSTOR and scopus. Behav. Soc. Sci. Libr. 2014, 33, 77-90. [CrossRef]

65. Shaw, R.D. The influence of anti-politics on arts education policy. Arts Educ. Policy Rev. 2020, 1-12. [CrossRef]

66. Veretekhina, S.V.; V. Krapivka, S.; I. Kireeva, O. Digital university, student's digital footprint, digital education currency in the system of modern higher education. Int. J. Psychosoc. Rehabil. 2020, 24, 1878-1889. [CrossRef]

67. Seeber, M.; Meoli, M.; Cattaneo, M. How do european higher education institutions internationalize? Stud. High. Educ. 2020, 45, 145-162. [CrossRef]

68. Wrigley, C.; Wolifson, P.; Matthews, J. Supervising cohorts of higher degree research students: Design catalysts for industry and innovation. High. Educ. 2020, 1-20. [CrossRef]

69. Westerlund, H.; Barrett, M. Narrating arts education research impact in and through research policy: Affordances and constraints for professional transformation. Arts Educ. Policy Rev. 2020, 1-13. [CrossRef]

70. Edgar, S.N.; Morrison, B. A vision for social emotional learning and arts education policy. Arts Educ. Policy Rev. 2020, 1-6. [CrossRef]

71. Helton, B.C. The arts' legitimacy problem. Arts Educ. Policy Rev. 2020, 1-15. [CrossRef]

72. Kummanee, J.; Nilsook, P.; Wannapiroon, P. Digital learning ecosystem involving STEAM gamification for a vocational innovator. Int. J. Inf. Educ. Technol. 2020, 10, 533-539. [CrossRef]

73. Lambert, P.A. The order-Chaos dynamic of creativity. Creat. Res. J. 2020, 32, 431-446. [CrossRef]

74. Wang, M.H.; Fu, H.Z.; Ho, Y.S. Comparison of universities' scientific performance using bibliometric indicators. Malays. J. Libr. Inf. Sci. 2011, 16, 1-19.

75. Bularga, T. The challenges of implementing a formative and innovative praxeology in artistic education. Rev. Artist. Educ. 2019, 18, 309-323. [CrossRef]

76. Mikalef, P.; Gupta, M. Artificial intelligence capability: Conceptualization, measurement calibration, and empirical study on its impact on organizational creativity and firm performance. Inf. Manag. 2021, 58, 103434. [CrossRef]

77. Orr, S. Researching design pedagogies that enhance creativity. Art Des. Commun. High. Educ. 2020, 19, 3-7. [CrossRef]

78. Chang, M.-L.L. Emotion display rules, emotion regulation, and teacher burnout. Front. Educ. 2020, 5, 100656. [CrossRef]

79. Han, H.-C. (Sandrine) The third culture. In Convergence of Contemporary Art, Visual Culture, and Global Civic Engagement; IGI Global: Hershey, PA, USA, 2017; pp. 318-330, ISBN 9781522516668.

80. Hanaee, J.; Rashidi, M.R. Higher education system in light of Covid-19. Pharm. Sci. 2020, 26, S1-S2. [CrossRef]

81. Lemonchois, M. Artistic Practical activities in art education. Palíndromo 2021, 13, 75-89. [CrossRef]

82. Fancourt, D.; Garnett, C.; Spiro, N.; West, R.; Müllensiefen, D. How do artistic creative activities regulate our emotions? Validation of the Emotion Regulation Strategies for Artistic Creative Activities Scale (ERS-ACA). PLoS ONE 2019, 14, e0211362. [CrossRef] 